\title{
Implementation of Fuzzy Tsukamoto Algorithm in Determining Work Feasibility
}

\author{
Mochammad Iswan Perangin-Angin, Andre Hasudungan Lubis, \\ Imelda Sri Dumayanti, Raheliya Br. Ginting, Andysah Putera Utama Siahaan \\ Faculty of Computer Science, Universitas Pembangunan Panca Budi, Medan, Indonesia \\ Faculty of Engineering, Universitas Medan Area, Medan, Indonesia \\ Faculty of Computer Science, Universitas Methodist Indonesia, Medan, Indonesia \\ Department of Informatics, Politeknik Poliprofesi Medan, Medan, Indonesia \\ Student of Universiti Malysia Perlis, Kangar, Malaysia \\ Corresponding Author: Mochammad Iswan Perangin-Angin
}

\begin{abstract}
The process of determining eligibility for someone is usually given with the same value. The determination of eligibility is determined based on several criteria. These criteria are the ability to Academic Potential Test (APT) and Grade Point Average (GPA). The Tsukamoto fuzzy system is the model used in this paper. Each input variable is divided into two membership functions. There are nine rules of Tsukamoto's model applied. The system also provides following changes of parameters if the parameter values are to be changed. The result of the difference of the employability is given to them. The greater the APT score, the more the value of the feasibility of the work obtained. The more GPA values gained, the greater the value of the workplace eligibility.
\end{abstract}

Keywords: Fuzzy, Tsukamoto, Expert System, DCS

Date of Submission: 20-07-2017

Date of acceptance: $28-07-2017$

\section{Introduction}

Recruitment is an activity to find as many candidates as possible with the available vacancies. Recruitment is the process of finding and attracting applicants to be employed within and by an organization. The purpose of recruitment is to get as much inventory of applicants as possible so that the organization will have a greater chance of making a choice against a prospective worker who is deemed to meet the organization's qualification standards. Based on these insights, recruitment can be defined as the process of finding, finding and attracting applicants to be employed in and by an organization as a first step in occupying a job [6].

Selection is an activity of the company to select the right candidate and eliminate applicants who are considered inappropriate to be accepted in a work organized or company. The selection process is a systematic effort to ensure that those who are accepted are the most appropriate. In this work placement process, there is often a problem between the company and the prospective worker, such as the high demand of the company but the ability of the candidate is not eligible and vice versa the ability of the candidate is high, but the company does not provide a decent salary [7]. Given this problem, often does not create a real work process. Tsukamoto is one of the fuzzy techniques [5]. By applying the Tsukamoto method, the existing problems can be solved well.

\section{Theories}

\subsection{Fuzzy Logic}

Fuzzy logic is a good choice to generatean input space into an output space by the abstract input values. Fuzzy logic is easy to learn. There is not many rules to apply in it. Only a few steps, the formula generates the output desired [1].

Fuzzy logic system has four elements:

- $\quad$ The basic rule that contains the rules derived from the experts.

- A decision-making mechanism in which the expert took the decision to apply the knowledge they have.

- $\quad$ A Fuzzification process. It converts the original crisp value into the magnitude fuzzy crisp.

- A Defuzzification process.The process to return the fuzzy value into crisp value as the result of fuzzy process.

Fuzzy has three components, fuzzification, fuzzy inference, and defuzzification [2]. Fuzzy logic has a membership function that consists of the limit value of data input and output data value [3]. The definition of a membership function is a graph that there are points from the limit of the input data value in a membership value that is worth between 0 and 1 . 
There are three parts to the membership function, core, support, and boundary [4]. The core section is the graphic section that states the complete region of the entire fuzzy set. $X$ is a member of set $\mu(x)=1$. The next section is support, support is the graphic section that states the region with a membership value instead of 0 of the fuzzy set. It is expressed in a function in which $\mathrm{x}$ is a set of $\mu(\mathrm{x})>0$ members. The last section is the boundary, boundary in the membership function graph is the minimum limit value and the maximum limit of the fuzzy set. It is expressed in the function where $\mathrm{x}$ is a set member is $0<\mu(\mathrm{x})>1$.

\subsection{Tsukamoto}

Tsukamoto method is one of the methods of Fuzzy Inference System. In this method, it uses the causeeffect rule or "if-then" [5]. The calculation method of the Tsukamoto fuzzy method is a rule formed representing the fuzzy set, then calculated the degree of membership in accordance with the rules that have been made. After obtaining the degree of membership, the predefined alpha value $(\alpha)$ will be obtained by finding the minimum value of the membership degree. Then, it will look for an output value which is a crisp value called defuzzification process, which is expressed in the following equation.

$$
Z=\frac{\sum \alpha(i) \cdot z(i)}{\sum z(i)}
$$

Where:

$$
\begin{array}{ll}
\alpha & =\text { alpha } \\
\mathrm{Z} & =\text { crisp value } \\
\mathrm{Z} & =\text { defuzzification }
\end{array}
$$

\section{Methodology}

The method used is Tsukamoto. The membership function used is linear. Linear means triangle and trapezium. Each of the input variables is divided into two membership functions. The first test for APT is divided into two membership functions, low and high. The second for GPA is divided into two membership functions that are good and bad. From each variable, it will give each of the two membership functions shown in the following figures:

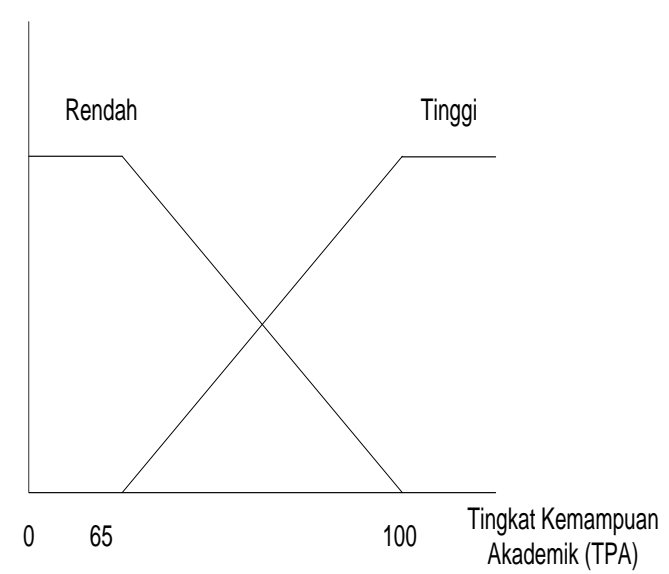

Figure 1. APT membership function

$$
\begin{gathered}
\text { F_Low (TPA) }=\left\{\begin{array}{cc}
1 ; & x \leq 65 \\
\frac{100-x}{100-65} ; & 65 \leq x \leq 100 \\
0 ; & x \geq 65
\end{array}\right. \\
\text { F_High (TPA) }=\left\{\begin{array}{rc}
0 ; & x \leq 65 \\
\frac{x-100}{100-65 ;} & 65<x \leq 100 \\
1 ; & x \geq 65
\end{array}\right.
\end{gathered}
$$




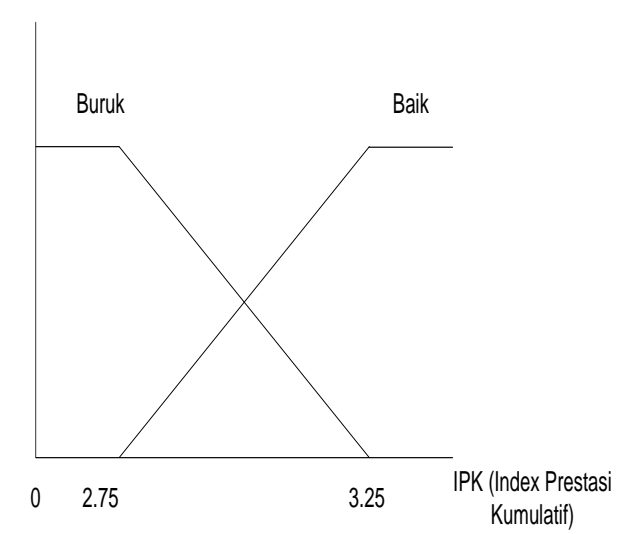

Figure 2. GPA membership function

$$
\begin{gathered}
\text { F_Worst (GPA) }=\left\{\begin{aligned}
1 ; & I P K \leq 2.75 \\
\frac{3.25-I P K}{3.25-2.75} ; & 2.75<I P K \leq 3.25 \\
1 ; & I P K \geq 3.25
\end{aligned}\right. \\
\text { F_Good (GPA) }=\left\{\begin{aligned}
0 ; & I P K \leq 2.75 \\
\frac{I P K-1.25}{3.25-2.75} ; & 2.75<I P K \leq 3.25 \\
1 ; & I P K \geq 3.25
\end{aligned}\right.
\end{gathered}
$$

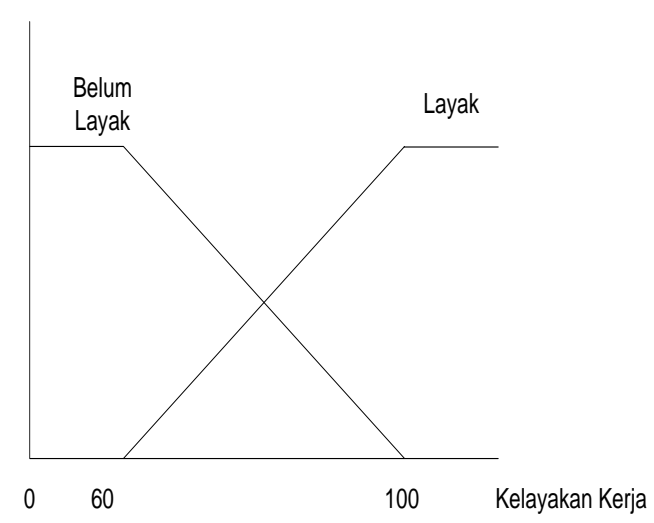

Figure 3. Work feasibility membership function

$$
\begin{aligned}
& \text { F_Less (WF) }=\left\{\begin{aligned}
1 ; & K K \leq 100 \\
\frac{100-K K}{100-60 ;} \quad & 60<K K \leq 100 \\
0 ; & K K \geq 100
\end{aligned}\right. \\
& \text { F_More (WF) }=\left\{\begin{aligned}
& 0 ; K K \leq 100 \\
& \frac{K K-60}{100-60 ;} \quad 60<K K \leq 10 \\
& 1 ; \quad K K \geq 60
\end{aligned}\right.
\end{aligned}
$$

Where:

$$
\begin{aligned}
\text { APT } & =\text { Academic Potential Test } \\
\text { GPA } & =\text { Grade Point Average } \\
\text { WF } & =\text { Work Feasibility }
\end{aligned}
$$

Table 1. Fuzzy Rule

\begin{tabular}{|c|c|c|c|}
\hline \multirow{2}{*}{$\begin{array}{c}\text { Rule } \\
\text { Nimber }\end{array}$} & \multicolumn{3}{|c|}{ Rule } \\
\cline { 2 - 4 } & APT & GPA & Work Feasibility \\
\hline 1 & Low & High & More \\
\hline 2 & High & High & More \\
\hline 3 & High & Low & Less \\
\hline 4 & Low & Low & Less \\
\hline
\end{tabular}


From table 1, there is a value of the degree of output membership of each rule to see detailed rules of fuzzy logic. After obtaining the number of rules by using Tsukamoto, there are two rules by using the AND operator. After searching the value of membership degree from the output of each rule created or generated from the combined of APT and GPA. The next step is to find the value of the work feasibility of each rule that is in table 1 .

\section{Evaluation}

From the system that researchers do, there are scores of GPA and test of different APT also from every person who was ranked the top five.

Table 2.Initial Data

\begin{tabular}{|c|l|c|c|c|}
\hline No. & Name & APT & GPA & WF \\
\hline 1 & Mesran & 80 & 3.23 & Ok \\
\hline 2 & Robbi & 85 & 3.20 & Ok \\
\hline 3 & Solly & 85 & 3.17 & Ok \\
\hline 4 & Dodi & 90 & 3.12 & Ok \\
\hline 5 & Melly & 75 & 3.08 & Ok \\
\hline
\end{tabular}

Table 3. Work Feasibility after using fuzzy Tsukamoto

\begin{tabular}{|c|l|c|l|l|l|}
\hline No. & Name & APT & GPA & WF & WF (Fuzzy) \\
\hline 1 & Mesran & 80 & 3.23 & Ok & Ok \\
\hline 2 & Robbi & 85 & 3.20 & Ok & Ok \\
\hline 3 & Solly & 85 & 3.17 & Ok & Ok \\
\hline 4 & Dodi & 90 & 3.12 & Ok & Ok \\
\hline 5 & Melly & 75 & 3.08 & Ok & Not Ok \\
\hline
\end{tabular}

Table 2 shows an example of work ability taken as initial values before fuzzy. The calculation is still by way of equal distribution, and there is no difference in the feasibility of work gained. Of these values, it is rather difficult to encourage those whose their APT is little to improve their work performance further because they have the same work worthiness. In Table 3, there is a different feasibility of work because it is calculated using Tsukamoto, which is based on two variables, APT and GPA. Each variable has the lower limit and upper limit respectively. For the results of the feasibility of work also has the upper limit and lower limit in the process of issuing the value of work worthiness for students who get it.

\section{Conclusion}

The method of determining the feasibility value of work that has been running before is still not good and less clear based on what they get the value of work eligibility because the previous system that has been running still use one variable to determine the feasibility of work. Fuzzy Tsukamoto aims to provide a work worthiness value varying according to the specified variable if a person has a high GPA and low APT get a high workability but for students who have high GPA and high APT get a high workplace feasibility but not as much as those with low landfill students.

\section{Reference}

[1] O. S. Widayanti Deni and A. Sasmita, "Analysis and Implementation Fuzzy Multi-Attribute Decision Making SAW Method for Selection of High Achieving Students in Faculty Level," IJCSI International Journal of Computer Science Issues, vol. 10, no. 1, pp. 674-680, 2013.

[2] M. Iswan, Khairul and A. P. U. Siahaan, "Fuzzy Logic Concept in Technology, Society, and Economy Areas in Predicting Smart City," International Journal of Recent Trends in Engineering \& Research, vol. 2, no. 12, 2016.

[3] A. P. U. Siahaan, "Fuzzification of College Adviser Proficiency Based on Specific Knowledge," International Journal of Advanced Research in Computer Science and Software Engineering, vol. 6, no. 7, pp. 164-168, 2016.

[4] Khairul, M. Simaremare and A. P. U. Siahaan, "Decision Support System in Selecting The Appropriate Laptop Using Simple Additive Weighting," International Journal of Recent Trends in Engineering and Research, vol. 2, no. 12, pp. 215-222, 2016.

[5] A. Saepullah and R. S. Wahono, "Comparative Analysis of Mamdani, Sugeno And Tsukamoto Method of Fuzzy Inference System for Air Conditioner Energy Saving," Journal of Intelligent Systems, vol. 1, no. 2, pp. 143-147, 2015.

[6] J. W. Omolo, M. N. Oginda and W. Y. Oso, "Effect of Recruitment and Selection of Employees on The Performance of Small and Medium Enterprises in Kisumu Municipality, Kenya," International Journal of Human Resource Studies, vol. 2, no. 3, pp. 139-150, 2013.

[7] A. S. Gamage, "Recruitment and Selection Practices in Manufacturing SMEs in Japan: An Analysis of the Link with Business Performance," Ruhuna Journal of Management and Finance, vol. 1, no. 1, pp. 37-52, 2014

Mochammad Iswan Perangin-Angin. "Implementation of Fuzzy Tsukamoto Algorithm in Determining Work Feasibility." IOSR Journal of Computer Engineering (IOSR-JCE) 19.4 (2017): 52-55. 